\title{
Lung Lymphoma
}

National Cancer Institute

\section{Source}

National Cancer Institute. Lung Lymphoma. NCI Thesaurus. Code C4794.

A rare non-Hodgkin or Hodgkin lymphoma that arises in and is confined to the lung at the time of diagnosis. 